\title{
O exilio e a emigración na base da Editorial Galaxia dende a súa creación ata a década dos sesenta. O caso de Arxentina e Uruguai
}

\author{
Exile and Emigration: Tenets of Editorial Galaxia from its Foundation \\ until the 1960's. The Case of Argentina and Uruguay
}

\author{
María Dolores Villanueva Gesteira \\ Universitat de Barcelona \\ Departament de Filologia Romànica \\ malores@gmail.com
}

[recibido 31/10/2014, aceptado 08/02/2015]

No olvides que en ciertos aspectos estamos en el fin del mundo, o mejor del otro lado del mundo, lejos de todo. (Luís Seoane a Fernández del Riego* Buenos Aires 22/05/1950)

\section{RESUMO}

Arxentina e Uruguai, como principais países receptores da emigración e do exilio galegos, axudaron a asentar o proxecto da Editorial Galaxia durante dúas décadas con achegas económicas e coa divulgación dos libros publicados. A relación entre a Galicia interior e a exterior era intensa, polo que foi posible levar a cabo accións comúns.

PALABRAS CHAVE: Editorial Galaxia, exilio, emigración, culturalismo.

\section{RESUMEN}

Argentina y Uruguay, como principales países de emigración y exilio gallegos, ayudaron a cimentar el proyecto de la Editorial Galaxia durante dos décadas con ayudas económicas y con la divulgación de los libros publicados. La relación entre la Galicia interior y la exterior era intensa, por lo que fue posible llevar a cabo acciones comunes.

PALABRAS CLAVE: Editorial Galaxia, exilio, emigración, culturalismo.

\begin{abstract}
Argentine and Uruguay helped to set the Editorial Galaxia project as the main migrant-receiving countries from Galician exile. For two decades, they collaborated with financial support as well as spreading published books. The relationship between "inland Galicia" and "Galicia abroad" was strong; therefore it was possible to perform common actions.
\end{abstract}

KEY WORDS: Editorial Galaxia, exile, emigration, culturalism.

Villanueva Gesteira, Ma D. (2015): “O exilio e a emigración na base da Editorial Galaxia dende a súa creación ata a década dos sesenta. O caso de Arxentina e Uruguai”, Madrygal (Madr.), 18, Núm. Especial: 529-537.

SUMARIO: 1. Introdución. 2. O apoio exterior á Editorial Galaxia. 3. Conclusións. 4. Referencias bibliográficas.

\footnotetext{
* As cartas recollidas neste artigo poden consultarse na Biblioteca Francisco Fernández del Riego. A correspondencia entre Luís Seoane e Fernández del Riego está publicada (Fernández del Riego 2002), pero neste artigo citaremos polos orixinais debido aos problemas de transcrición das cartas, con omisións e cunha tradución ao galego non sempre fiel.
} 


\section{INTRODUCIÓN}

En Buenos Aires na década dos 50 había máis galegos ca en calquera cidade de Galicia. De feito, entre 1911 e 1934 Arxentina foi o primeiro país receptor de emigrantes, e entre 1946 e 1950 o $55 \%$ da emigración galega instalouse alí. Dos anos 1941 ó 1945 a media de emigrantes galegos foi de 697, cifra que se incrementou moito entre 1946 e 1950 onde a media ascendeu ata 13360 . Uruguai tamén acaparou boa parte desas migracións e entre 1940 e 1960 foron máis de 50000 os galegos establecidos no país ${ }^{1}$. Eran estados en pleno desenvolvemento e, naquel momento, os principais provedores de gran e carne para unha Europa devastada pola guerra, pero tamén avanzaban coa crecente industralización. Por outra banda, os exiliados tamén elixiron Arxentina como destino predilecto motivados pola importante presenza galega e alí desenvolveron un papel político e/ou cultural moi activo. Loxicamente a gran masa de emigrantes e exiliados compoñen un conglomerado moi diverso imposible de codificar nunhas liñas, pero quizais si nestas palabras de Luís Seoane:

Observo que la prensa de ahí y en general los amigos suponen un extraordinario movimiento cultural en esta, y la realidad es que de los cuatrocientos mil emigrados que hay aproximadamente apenas trabajamos en esto unos quince, que estamos consiguiendo lo que podemos con toda la habilidad de que somos capaces. Galicia no puede contar con la gente emigrada, sinó en una parte mínima, para nada de lo que se desea realizar en beneficio de ella. (...) Nosotros luchamos por crear un gran impulso colectivo en beneficio de una mayor intervención del emigrado en la vida cultural de Galicia pero fracasamos, aunque no del todo, por distintos motivos, en este esfuerzo. Tropezamos sobre todo con el porcentaje enorme de gente indiferente a Galicia que desarrollan su vida exclusivamente atendiendo a sus intereses personales tratando de incorporarse a este país, lo cual es natural, y de olvidar el origen, lo que ya no es tan natural, con la falta de una cultura mínima referida a
Galicia de casi la totalidad y con la desconfianza y el personalismo característico entre ellos (...) Yo estoy orgulloso de sentirme hermano de estos hombres que llegan a esta campesinos casi analfabetos, y logran, por su inteligencia y su esfuerzo ocupar un primer lugar en la industria y el comercio, en lucha permanente con climas y razas distintas e incluso con la dificultad del idioma y de su psicología de hombres que han sido dominados por el desprecio y la indiferencia. Creo en su esfuerzo individual, en su ingenio, en su capacidad de adaptación pero también los creo incapaces de un esfuerzo colectivo por Galicia, porque si bien la aman y sienten nostalgia de ella, no creen en ella y desconfían de ella y solo una minoría muy minoría sueña con volver a vivir a Galicia, a los más solo les interesa como lugar de turismo y descanso circunstancial o prefieren la tortura de su recuerdo. Temen al señoritismo, temen al desprecio y temen volver a los propios orígenes. Por esto creo yo que hay que elogiar todo lo que hagan en beneficio de Galicia, pero sin dar en esa la sensación de que puede esperarse de ellos mucho más de lo que se puede hacer ahí mismo. Aquí, hasta ahora, no se hizo nada importante sobre todo si pensamos en la capacidad humana y económica de esta colectividad. De todas maneras no comentes esto ni lo de la carta. (Carta de Luís Seoane a Fernández del Riego², Buenos Aires 24/11/1950)

Luís Seoane quéixase, no seu discurso privado, da situación en Buenos Aires e di aborrecer a cidade, as súas xentes, o clima, como queda constancia no seu epistolario. Unha actitude de rexeitamento que se dá tamén noutros exiliados como Rafael Alberti, que remata por trasladarse de Arxentina a Italia, antes de que se dese a posibilidade de regresar a España. Unha saudade constante, que se converte en ansiedade por volver e nunha sensación continuada de frustración, de amputación da felicidade que se repite nas biografías dos exiliados. Non atopan na colectividade galega o apoio e o recoñecemento que buscaban e así centraron parte dos seus esforzos en tarefas que tiñan que ver con Galicia, como a creación e o sustento da Editorial Galaxia.

\footnotetext{
${ }^{1}$ Para máis información pódese consultar os traballos de P. Cagiao Vila (2013).

${ }^{2}$ Carta do Arquivo Francisco Fernández del Riego, con sinatura FR-CA-030.
} 
En 1940 chegaran á dirección do Centro Galego de Buenos Aires un sector galeguista de nomes tan significados como Rodolfo Prada, Manuel Puente ou José Abraira, e con eles asumiron a Comisión de Cultura figuras tan relevantes como Arturo Cuadrado ou Luís Seoane. Este último levaba naqueles anos o peso cultural do Centro Galego, dirixía a revista Galicia, que tiña unha tiraxe de 50000 exemplares, xestionaba os premios ou editaba obras de interese. Despois ocuparíase Blanco Amor, quen asume a dirección da revista en 1957, e nas dúas etapas recibían as colaboracións dos intelectuais galeguistas, que estaban capitaneadas por Francisco Fernández del Riego, home ponte entre a diáspora e o interior.

Outra das funcións do Centro Galego era invitar a unha das personalidades do país para ofrecer unha serie de conferencias e así reforzar os vínculos con Galicia. Normalmente visitaban Buenos Aires, pero tamén Montevideo, onde contaban coa Casa de Galicia, o Centro Galego e o Padroado da Cultura Galega. Estas viaxes aproveitábanas os homes de Galaxia para dar a coñecer a editorial, sumar esforzos en diferentes proxectos, aumentar as subscricións e tamén o número de accionistas.

Alén mar afanábanse en traballar no eido cultural para que a vinculación non se perdera, para sentírense recoñecidos pola colectividade, pero tamén na terra que tiveron que abandonar. Por exemplo, Seoane e Cuadrado crearon un importante tecido editorial coa fundación, nos anos corenta, da Editorial Nova e da Editorial Botella al Mar, ambas as dúas dedicadas a publicar, en parte, libros galegos. E xa antes crearan e dirixiran as coleccións "Dorna" e "Hórreo" na Editorial Emecé.

\section{O APOIO EXTERIOR Á EDITORIAL GALAXIA}

Nesa mesma idea de crear unha editorial na que vehicular a cultura galega tamén van cadrar Francisco Fernández del Riego e Xaime Isla, promotores da Editorial Galaxia que fundaron en 1950. Contou dende o inicio co apoio da colectividade de emigrantes e exiliados; polo mesmo debemos evitar lecturas maniqueas e simplistas que levan a confrontar os proxectos do interior e do exilio como paralelos, enfrontados e que non se tocan en ningún punto. Isto levou á mitificación do exilio e á condena das accións levadas a cabo no país, pero a pouco que nos acheguemos a este tema verase que hai unha colaboración permanente e que as friccións danse entre exilio e interior, pero tamén dentro de cada realidade, onde había xente moi heteroxénea e con visións moi diferentes.

En cierto modo estamos envidiosos de la labor que realizáis ahí con las Ediciones Galaxia, Benito Soto, Bibliófilos Gallegos y las revistas de poesía. Es este un ejemplo que aquí no saben entenderlo y que en el fondo desdeñan. Es la labor que habíamos emprendido Cuadrado y yo hace años con el afán de convertir esta ciudad en un gran centro editorial gallego y en la que fracasamos después de publicar unos 60 libros gallegos por falta del más mínimo apoyo de las gentes que en cambio realizan banquetes culturales. (Carta de Luís Seoane a Fernández del Riego $^{3}$, Buenos Aires 13/06/1951).

Son innumerables as cartas nas que se festexa, por parte da diáspora, a chegada dos libros de Galaxia e o propio proxecto:

Os libros de Galaxia recíboos puntualmente e deles me ocupo sempre na audición "Sempre en Galiza". Tamén recibo a Revista de Economía que está, en xeral, moi ben, é moi útil e enche un grande valdeiro. (Carta de Lois Tobío a Fernández del Riego, Montevideo $10 / 08 / 1961)^{4}$.

Se Lois Tobío se ocupaba das audicións en Uruguai, Luís Seoane facía o propio na Arxentina onde, a través dos comentarios radiais para as audicións de "Galicia Emigrante", daba conta dos libros publicados en Vigo.

\footnotetext{
${ }^{3}$ Carta do Arquivo Francisco Fernández del Riego, con sinatura FR-CA-030.

${ }^{4}$ Carta do Arquivo Francisco Fernández del Riego, con sinatura FR-CA-031/021.
} 
No ano 1954 foi convidado Fernández del Riego, un dos fundadores de Galaxia e naquel momento secretario e xerente da empresa. Amais das conferencias impartidas, non desaproveitaba a ocasión para buscar apoios entre a colectividade; así o conta Neira Vilas cando lembra que "incorporaron naqueles días algúns accionistas e prometeron conseguir subscritores, pero, ao que parece, pouco ou nada avanzaron niso" (Longhini 2013: 14). Xa na primeira reunión da editorial, celebrada o 18 de agosto de 1950, acordárase recadar accionistas que desembolsasen o importe das accións inscritas cun pago mensual de 100 pesetas por cada unha. O capital social era de 500000 pesetas en 500 accións de 1000 pesetas cada unha. Nun primeiro momento non se chegaron a cubrir e poucas foron as que viñeron de alén mar.
Segundo a documentación manexada naquel ano, 1954, fixéronse accionistas de Galaxia 17 persoas en Uruguai, pero puideron ser algunhas máis, pois faltan datos nalgunhas fichas, en concreto os referidos á data de escrituración. Tamén discreto era o número de subscritores, 26 entre os dous países:

Ya tengo noticia de la labor de Galaxia. También llegó a mis manos un prospecto de unas ediciones "Monterrey". Hace días le escribí a Valentín y le preguntaba si hay aquí un representante o alguna casa que tenga esas publicaciones. En las librerías no se ven. Comprenderás que aunque se sepa que existen, no es fácil adquirirlas. Los mismos libros del Centro Gallego no se han vendido en las librerías, sino en la secretaría del Centro. Con todos los respectos debidos, me parece un criterio

\begin{tabular}{|c|c|c|}
\hline Apelidos, profesión & $\mathrm{N}^{\mathrm{o}}$ de acción & Data escrituración \\
\hline Crestar Faraldo, Antonio (Empresario, Montevideo) & 35 & $30 / 8 / 1954$ \\
\hline Meilán Martínez, Manuel (Empresario, Montevideo) & 45 & - \\
\hline Bello Luaces, Joaquín (Montevideo) & 48 & $1 / 10 / 1954$ \\
\hline Martínez González, Manuel M. (Empresario, Montevideo) & 71 & $30 / 8 / 1954$ \\
\hline Lamas Carreras, Antonio (Montevideo) & $78-79$ & $30 / 8 / 1954$ \\
\hline Moreira Casas, Venancio (Montevideo) & 106 & $30 / 8 / 1954$ \\
\hline Couceiro Corral, Pedro (Químico, Montevideo) & 110 & $30 / 8 / 1954$ \\
\hline Martínez Gómez, Marcelino (Empresario, Montevideo) & 130 & $3 / 8 / 1954$ \\
\hline Canabal Fuentes, Andrés (Montevideo) & 145 & $30 / 8 / 1954$ \\
\hline Valiño Sueiro, Antón (Deputado e médico, Montevideo) & $175-176$ & $7 / 5 / 1955$ \\
\hline Cababal Fuentes, Manuel (Industria Papelera Uruguaia S.A., Montevideo) & 180 & $30 / 8 / 1954$ \\
\hline Canabal Fuentes, José (Industria Papelera Uruguaia S.A., Montevideo) & $195-196$ & - \\
\hline Leiras Méndez, Manuel (Xerente Banco de seguros do Estado, Montevideo) & 199 & $30 / 8 / 1954$ \\
\hline González Martínez, José (Montevideo) & 216 & $5 / 11 / 1951$ \\
\hline Cantero Martínez, Ramiro (Montevideo) & 228 & $30 / 8 / 1954$ \\
\hline Martinich, Pedro (Montevideo) & 434 & $30 / 8 / 1954$ \\
\hline Canabal Fuentes, Jesús (Industria Papelera Uruguaia S.A., Montevideo) & $436-43 / 453-4$ & $30 / 8 / 1954$ e $14 / 7 / 1956$ \\
\hline Pérez, Marcelino ( Montevideo) & 444 & Antes de 1960 \\
\hline Comesaña Giráldez, Eugenio (Montevideo) & 447 & $30 / 8 / 1954$ \\
\hline Añón Canedo, José (Empresario, Montevideo) & 448 & $25 / 7 / 1954$ \\
\hline Martínez Castro, Juan (Empregado multinacional, Montevideo) & 449 & $30 / 8 / 1954$ \\
\hline Cancela Feijóo, José (Médico, Montevideo) & $451-452$ & $31 / 10 / 1955$ \\
\hline Canabal Fuentes, Jesús (Montevideo) & $436-43 / 453-4$ & $30 / 8 / 1954$ e $14 / 7 / 1956$ \\
\hline García, Maximino (Montevideo) & 445 & Antes de 1960 \\
\hline
\end{tabular}

Tabela 1. Accionistas en Uruguai (elaboración propia) 
equivocado. (Carta de Manuel Fuentes a Fernández del Riego ${ }^{5}$, Buenos Aires 24/12/1951).

Quizais polos problemas de distribución dos libros, naquela viaxe Del Riego instou ós máis novos, nunha reunión coas Mocedades Galeguistas, a que axudasen a divulgar os títulos entre a colectividade. Será desa idea da que nace Follas Novas, como relata Neira Vilas, para contribuír co labor de Galaxia a través dunha canle propia asentada en Buenos
Aires. El e Anisia Miranda inauguran o 15 de xullo de 1957 Follas Novas, onde recibían os libros en depósito o primeiro ano e despois facían compras en firme. O casal permaneceu en Buenos Aires ata o 30 de xuño de 1961, pero Follas Novas quedou en mans de Elsa Fernández, que contou co apoio de Antón Represas.

Neira Vilas di que, dende o inicio da actividade de Galaxia, en Buenos Aires había máis de cincuenta accionistas (Longhini 2013:22),

\section{Apelidos, profesión}

\begin{tabular}{l|l}
$\mathrm{N}^{\mathrm{o}}$ de acción & Data escrituración
\end{tabular}

\begin{tabular}{|c|c|c|}
\hline Pulpeiro Villamil, Eliseo (Buenos Aires) & 213 & $22 / 8 / 1956$ \\
\hline López, Perfecto (Comerciante, Buenos Aires) & 377 & $12 / 1 / 1949$ \\
\hline Vázquez Penabad, José F. (Comerciante, Buenos Aires) & $378-379$ & $20 / 5 / 1950$ e $30 / 8 / 1954$ \\
\hline Puente, Manuel (Industrial, Buenos Aires) & 380-389 & $25 / 7 / 1950$ \\
\hline Abraira, José Benito (Buenos Aires) & 390 & $6 / 8 / 1953$ \\
\hline Alfonso Reboreda, José (Buenos Aires) & $391-392$ & - \\
\hline Alonso Pérez, Antonio (Buenos Aires) & 393-394 & - \\
\hline Prada Chamochín, Rodolfo (Axente comercial, Buenos Aires) & $397-8 / 430-32$ & $25 / 7 / 1953$ \\
\hline Vázquez Iglesias, Javier (Buenos Aires) & $399-408$ & $25 / 7 / 1953$ \\
\hline Ucha Rodríguez, Manuel (Buenos Aires) & $414 / 455$ & $6 / 8 / 1953$ \\
\hline Valenzuela Otero, Ramón (Buenos Aires) & 416 & $6 / 8 / 1953$ \\
\hline Nogueira, Daniel (Buenos Aires) & 417 & $6 / 8 / 1953$ \\
\hline Iglesias Rivadulla, José (Buenos Aires) & 419 & $6 / 8 / 1953$ \\
\hline Fernández, Félix (Médico, Buenos Aires) & $420-1$ & $6 / 8 / 1953$ \\
\hline García, Eugenio (Buenos Aires) & $422-423$ & $7 / 8 / 1953$ \\
\hline Represas, Antonio (Buenos Aires) & $425-9$ & $28 / 1 / 1953$ \\
\hline Prada Camochín, Rodolfo (Axente comercial, Buenos Aires) & $397-8 / 430-32$ & $25 / 7 / 1953$ \\
\hline Otero, Elías (Buenos Aires) & 433 & - \\
\hline Dapresa Esmerode, Moisés (Buenos Aires) & 435 & - \\
\hline López Romero, Perfecto ( Xornalista, Buenos Aires) & $463-467$ & $15 / 10 / 1958$ \\
\hline Mourente, Ramón (Buenos Aires) & $474-483$ & $13 / 11 / 1961$ \\
\hline Díaz, Antón (Arxentina) & $485-486$ & $6 / 8 / 1953$ \\
\hline Nogueira, Daniel (Buenos Aires) & 417 & - \\
\hline Santiago Rodríguez, José (Buenos Aires) & $412-413$ & - \\
\hline Santiago García, Silvio (Arxentina) & 261 & - \\
\hline Rodríguez, Antón (Buenos Aires) & - & - \\
\hline Maseda, Rosendo (Buenos Aires) & - & - \\
\hline
\end{tabular}

Tabela 2. Accionistas en Arxentina (elaboración propia)

\footnotetext{
${ }^{5}$ Carta do Arquivo Francisco Fernández del Riego, con sinatura FR-CA-015.
} 
pero dende logo, á vista dos datos (Tabela 2), foron moitos menos. Na Arxentina foi en 1953 cando máis escrituracións de accións houbo, quizais porque aquela viaxe a alén mar a realizara García-Sabell, home da editorial, ou porque a anterior, en 1952, contara coa presenza do seu presidente, Ramón Otero Pedrayo. El era a persoa máis reclamada pola diáspora para esa viaxe pois, coa morte de Castelao, era o petrucio do galeguismo.

Teimarei facer as cousas ó millor que poido de tal xeito que iste viaxe e sacrificio non remate valeiro pro senso e porvir da galeguidade e axude o recoñecimento de valenza esenzal de "Galaxia" no mundo. (Carta de Otero Pedrayo a Fernández del Riego ${ }^{6}$, s.d.).

Otero e os demais membros da editorial eran conscientes nas viaxes do labor mesiánico, por dicilo dalgunha maneira, ó que eran chamados, pero, por outra, tamén da importancia de difundir a obra da editorial. Polo tanto, as viaxes a Buenos Aires e Montevideo eran unha mostra máis de compromiso co país, pero tamén unha maneira de sustentar a actividade no interior. Para eles, amosar Galicia era unha obriga moral, pero ademais servía de fonda axuda para conseguir compromisos cos proxectos que se desenvolvían e apoiar tamén coa súa presenza e o seu traballo o que se estaba a facer fóra.

Como xa dixemos, a través da empresa creada por Neira Vilas e Anisia Miranda, Follas Novas, vendíanse os libros nun mercado interesante para a editorial, porque había moitos galegos e un bo número deles tiña unha situación económica desafogada, o que permitía desembolsar na adquisición de libros. A situación do país axudaba a que se sufragasen proxectos dende a diáspora e isto axudou á precaria situación da editorial nos primeiros tempos. Así, sen o apoio de alén mar, non se terían dado a lume obras tan importantes como o Diccionario de Eladio Rodríguez ou a Revista de Economía de Galicia.
Acórdase xestionar cos centros e coleitividade de emigrados da América a posibilidade de que sufraguen os gastos da Revista de Economía ou, conseguir de determinados emigrados que siguen o noso movimento cultural unha aportación fixa que garantice a regularidade da pubricación e, ó mesmo tempo, percurar no pais a suscripción de entidades e organismos e continuar, como se ven facendo, as individuales. (Acta 277, Vigo 15/02/1959)

O nacemento da Revista de Economía de Galicia (1958-1968) abría unha vía para a reflexión dos principais problemas neste eido e estes temas eran de moito interese entre a colectividade; lembremos o comentario de Lois Tobío. No ano 1959 a revista recibe 50000 pesetas anuais da colectividade, 35000 da emigración arxentina e 15000 da uruguaia, que naquel momento eran moitos cartos e é moi probable que non só se destinasen a esa publicación.

En canto o compromiso contraido ante o amigo Piñeiro, por min e Perfecto [López], de axudar financieiramente a edición da "Revista de Economía de Galicia", podo adiantarlle que aproveitando a dita xuntanza, pranteamos a cuestión, é quedou resolto que Perfecto xuntaría 35.000.- Ptas. e eu en Montevideo 15.000.- Propuxen que entre o Banco e demais compañeiros aportaran 5.000.- e eu suscribíame con 10.000.Por unanimidade foi rechazada a proposta e quere ser o Banco que contribuia con toda a cantidade por tratarse dunha obra de moito mérito e que dacordo cos estatutos debe ser apoiada. (Carta de Jesús Canabal a Fernández del Riego, Montevideo 15/03/1959)

O Banco del Trabajo Italo Americano y Banco de Galicia de Montevideo colaboraba con 15000 pesetas, mentres na Arxentina Valentín Fernández e Manuel Puente recollían entre a colectividade as achegas puntuais, pero tamén as extraordinarias cando había que cubrir algunha necesidade.

$\mathrm{Xa}$ ve que non descuidamos ren.- E sería mui comenente que nos tiveran enterados

\footnotetext{
${ }^{6}$ Carta do Arquivo Francisco Fernández del Riego, con sinatura FR-CA-021.

${ }^{7}$ O primeiro Libro de Actas da Editorial Galaxia está depositado na sede da editora, sen catalogar.
} 
de calquera dificultade pra intervir oportunamente.- Non somentes no caso dos aportes a Galaxia, mais tamén en calquera outro e de calquera orden, pois así evitaríanse aititudes que producen efectos contrarios os que se pretende facer-- Ben dicen que non é mal xastre o que coñece o pano e como xa levamos moitos anos, unhas veces hilvanando, outras cosendo, e outras zurcindo, e algunha esperencia temos adquirida.- Poño esto no seu coñecemento por si o quixera teren en conta.- (...) Mándolle con esta unha lista dos que contribuiron,- fallan dous ou tres dos que non sei a direición -pra que lles envie unha carta agradecéndolles, e un exemprar da revista.- Xa lles entreguei un recibo a cada un, firmado ademais polos irmans Prada e Regueira; pro é mui comenente que a Editorial lles mande unhas letras conceituosas por si tivéramos que repetir o pedido.- Trátase polo demais de xentes que molestamos a miudo por razóns sempre patrióticas (...)

Manuel García: Pavón 16, Avellaneda / José Parafita: Mariano Acosta 264; Avellaneda / Manuel Pazos: Sarandi 847, Buenos Aires / Ateneo Curros Enríquez: Chacabuco 955, Buenos Aires / Manuel Casal: Lavalle 178, Buenos Aires / Vicente Velasco: Dean Funes 330, $3^{\circ}$ Buenos Aires / José Vilar: De las Ciencias 1142, Buenos Aires / Miguel C. Álvarez: Sáenz Peña, 251, Buenos Aires / Cosme Méndez: Belgrano esq. Pasco (Centro Gallego) Buenos Aires / Segundo Pampillón: Corrientes 550, $7^{\circ}$ V Buenos Aires / Rodolfo Prada: Constitución 4334, Buenos Aires / Darío Lamazares: Belgrano 1841, Lar Gallego, Buenos Aires / Carlos C. Vázquez Richart: Belgrano 2186, Buenos Aires / Antón Represas: Correa 2318, Buenos Aires / J. Fernández Caramés: Federico Lacroze esq. Corrientes (Confitería Imperio) Buenos Aires / Eugenio García (Centro Pontevedrés) Sarandi 847 / Juan Manuel Pérez: Hipólito Yrigoyen 2949, Buenos Aires / Manuel Arias: Montes de Oca 1672, Buenos Aires / Enrique A. González: Larsen 2540, Buenos Aires / Eduardo Sánchez Millares: Belgrano esq. Pasco (Centro Gallego), Buenos Aires / José do Casar: Belgrano esq. Pasco (Centro Gallego), Buenos Aires / Serafín Míguez Illobre: Belgrano esq. Pasco (Centro Gallego), Buenos Aires / José B. Iglesias: Paraguay 1439, Buenos Aires / Ramón Valenzuela Otero: Venezuela 452, $4^{\circ}$ Buenos Aires
/ José Alfonso Reboreda: Montiel 929, Buenos Aires / Valentín Fernández: José Bonifacio 483, Buenos Aires / Isidro Rodríguez Amoedo: Rufino Ortega 465, Mendoza (República Argentina) / Francisco Regueira. (Carta de José B. Abraira a Fernández del Riego ${ }^{8}$, Buenos Aires 09/11/1964).

Tamén os gravados incluídos na monografía de Maside, que publicou a Editorial Galaxia, foran pagados polo Centro Galego de Buenos Aires, por petición de Seoane, para aliviar a situación da editora. Polo tanto, as axudas prestadas e as relacións establecidas eran constantes e tamén se producían na outra dirección; é dicir, os membros de Galaxia colaboraban nas publicacións editadas alén mar e nos seus proxectos. Ás veces había tensións e desencontros, pois nin a distancia nin o tempo facilitaba o entendemento. Atopábanse cun desfase de adecuación polas dúas partes; así, en non poucas cartas hai reproches mutuos de idealización das situacións contrarias. Esta é unha das queixas:

Respecto a las colaboraciones en sí, veo que nuestros autores no se esfuerzan demasiado. Es peligroso el suponer que "se escribe para emigrantes". Nuestra colectividad, como tú muy bien sabes está trabajada intelectualmente por lo menos a la par de cualquier público selecto de una ciudad gallega. El concepto idílico y patriarcal que refleja el señor Carré en su discurso en la Academia, es absurdo y dejó de ser verdad; $y$ te lo cito como ejemplo de lo que parece ser el estado mental de nuestros escritores cuando se dirigen a nuestro pública de aquí. La colaboración de Risco, por ejemplo, es pueril, y la de Fole, llueve sobre mojado por cuanto las noticias que nos da nos las proporcionas tú, mes a mes, más extensas, intensas y mejor dichas. (Carta de Blanco Amor a Fernández del Riego", Buenos Aires 18/03/1958).

Un ano despois Blanco Amor escribíalle para que tivese en conta o paso do tempo e as mudanzas da colectividade, pois do total de socios do Centro Galego os que naceran na terra xa non superaban o $40 \%$, e xa o

\footnotetext{
${ }^{8}$ Carta do Arquivo Francisco Fernández del Riego, con sinatura FR-CA-001.

${ }^{9}$ Carta do Arquivo Francisco Fernández del Riego, con sinatura FR-CA-003.
} 
vicepresidente e outros membros da directiva eran arxentinos. Por iso reclamáballe colaboracións con temas máis xerais e coa posibilidade de que fosen en castelán, para contentar o maior número de persoas. Parece, polas cartas que se cruzan, que a percepción das partes tendía sempre á mitificación, pero a realidade era outra. De feito, nese mesmo ano de 1959, o Centro Galego inviste 300000 pesos na publicación do libro Obra completa de Ramón Cabanillas e as protestas dalgúns socios non tardaron en chegar pola importante inversión realizada. Este volume fora un proxecto fanado da Editorial Galaxia polos atrancos coa censura franquista, que prohibía "25 poemas de No desterro, Vento mareiro e Da terra asoballada e a totalidade da obra O Mariscal" (Rei 2009: 552). A idea da editora non se podía materializar no interior, pois sería unha edición amputada, e decidiron que vise a luz en Buenos Aires. A publicación deuse a lume tres días despois da morte do poeta, unha frustración para os amigos que loitaran tanto pola súa edición e que bateran reiteradamente coa prohibición. O traballo foi feito igualmente en Galicia, pois Fernández del Riego realizara a edición e tamén un limiar que acompañaba un estudo introdutorio de Carballo Calero. O Centro Galego de Buenos Aires unha vez máis colaborou cun proxecto da Editorial Galaxia.

Eu vou pedir 1.500 ptas. para Carballo Calero e outras tantas pra Iglesia Alvariño, polo seu traballo no libro de Cabanillas, e 1.000 pra ti. Teño o tema de que nadie traballe gratis. (Carta de Blanco Amor a Fernández del Riego $^{10}$, Buenos Aires 08/04/1960).

En contrapartida, tamén moitas das persoas que integraban o proxecto de Galaxia estaban subscritas a iniciativas do exterior, como á revista "Galicia emigrante", na que ademais asinaba artigos boa parte do galeguismo. Polo tanto, non podemos falar de accións illadas nin pechadas para a outra beira do Atlántico, senón, á vista dos datos, de proxectos que non só medraron co coñecemento mutuo, senón coa complicidade das partes. A vía cultural foi explotada aquén e alén mar e un proxecto como o de Galaxia non se pode entender sen o labor de apoio e de sustento da colectividade que vivía en Arxentina e Uruguai.

\section{CONCLUSIÓNS}

Aínda teñen peso no discurso cultural as lecturas maniqueas e simplistas que sitúan a Editorial Galaxia de costas á diáspora ou, incluso, como realidades completamente enfrontadas. Algo que dista moito da lectura da documentación conservada, a manexada como principal fonte bibliográfica neste artigo, que está integrada pola correspondencia e a documentación interna da editorial.

Así, atopamos un rico tecido de relacións que se mantiveron durante a ditadura franquista, cun diálogo intenso entre unha beira e outra do Atlántico. Loxicamente, está cheo de matices e de tensións porque, sen dúbida, hai dous imaxinarios culturais propostos, o do galeguismo do interior e o do exilio (GonzálezMillán 2007). Aínda así, as discrepancias non impediron que a diáspora apoiase proxectos como o da Editorial Galaxia, e non só o facía a emigración, senón tamén o exilio. Seoane, como pedra angular, pero tamén outros exiliados como Ramón Valenzuela, que aparece na listaxe de contribuíntes á empresa. Máis alá das discrepancias ideolóxicas ou políticas que puidesen ter cos galeguistas do interior, estaba a reconstrución cultural e política de Galicia que moitos deles entenderon como prioritaria.

As cousas mudaron a partir dos anos sesenta: por unha banda nin Arxentina nin Uruguai gozaban xa do esplendor económico anterior, por outra a emigración mudara moito, pero tamén as circunstancias no interior eran diferentes. Con todo, é innegable o esforzo por construír unha cultura propia, en galego, a unha beira e outra do Atlántico e o apoio que recibiu nos primeiros anos a Editorial Galaxia para poder manter proxectos ou sacar adiante outros que, pola censura, en Galicia serían inviables. Unha rede de ida e volta que construíu país, asentou institucións e alicerzou empresas.

\footnotetext{
${ }^{10}$ Carta do Arquivo Francisco Fernández del Riego, con sinatura FR-CA-003.
} 


\section{REFERENCIAS BIBLIOGRÁFICAS}

Cagiao Vila, Pilar (coord.) (2013): A emigración galega a América do Sur. A Coruña: Hércules de Ediciones.

Fernández del Riego, Francisco (2002): Cartas de Luís Seoane desde o exilio. Sada: Ediciós do Castro.

GónZALez Fernández, Helena (1994): Luís Seoane. Vida e obra. Vigo: Galaxia.

GonZÁlez-Millán, Xoán (2007): "Exilio, literatura e nación”, en X. M. Núñez Seixas e Pilar Cagiao Vila (eds.), O exilio galego de 1936: Política, sociedade, itinerarios. Sada / Santiago de Compostela: Ediciós do Castro / Consello da Cultura Galega, pp. 763-788.

Longhini, Nora (2008): Neira Vilas. Os anos da Arxentina 1949-1961. Textos recuperados. Vigo: Galaxia.

ReI, Luís (2009): Ramón Cabanillas. Crónica de desterros e saudades. Vigo: Galaxia. 